\title{
Clinical Molecular Genetic Laboratory Practice, Where We Stand in 2018
}

Meng $\mathrm{H}^{1}$ and $\mathrm{Xu} \mathbf{W}^{2 *}$

${ }^{1}$ Department of Cytogenetic and Genomics, Quest Diagnostics, Chantilly, VA 20152, USA

${ }^{2}$ Department of Molecular Genetics, True Health Diagnostics, Richmond, VA 23219, USA

*Corresponding author: Dr. Wenbo Xu, Department of Molecular Genetics, True Health Diagnostics, Richmond, VA 23219, USA, Tel: 734 591 1196; E-mail: WXu@truehealthdiag.com

Rec date: September 27, 2018; Acc date: October 05, 2018; Pub date: October 08, 2018

Copyright: (c) $2018 \mathrm{Meng} \mathrm{H}$. This is an open-access article distributed under the terms of the creative commons attribution license, which permits unrestricted use, distribution, and reproduction in any medium, provided the original author and source are credited.

He health system has been gradually evolving from patient-care to prevention-oriented medicine. he breakthroughs in the genomic technologies and database curation contribute signi icantly to the transformation. We enter the "genomic era" as we step on the blueprint of the irst human genome sequence. he growing role of genomics in healthcare for patient diagnoses, treatment, and disease prevention thrives with the global effort of personalized medicine; also called precision medicine. Meanwhile, we are facing challenges of the new model of health systems, insurance policies, and bioinformatics (Figure 1).

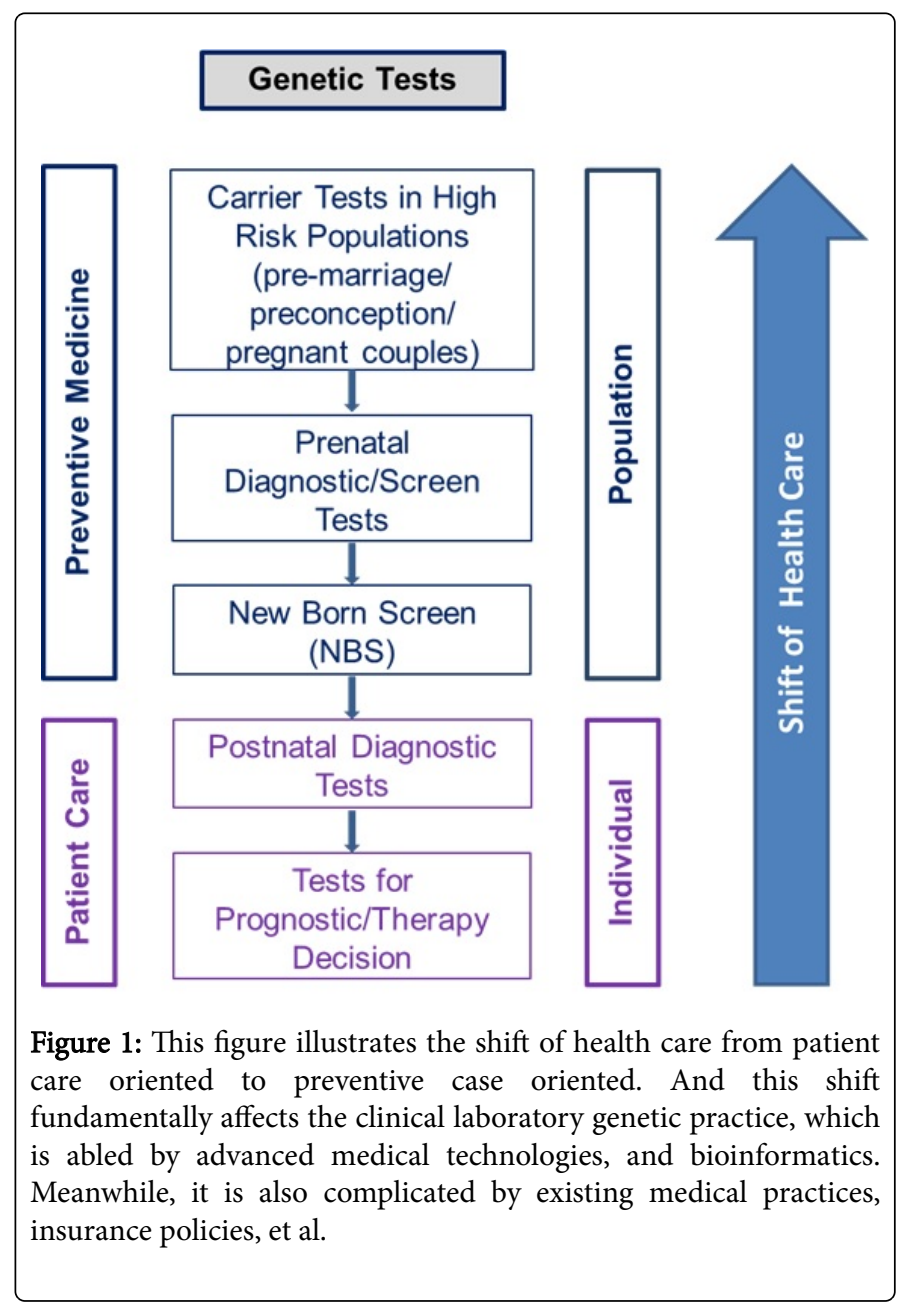

We have gradually learned that nearly all conditions and disorders have a genetic component. he technology has advanced from single gene Sanger sequencing to microarray, next generation sequencing (NGS) panel, exome sequencing, and most recently to whole genome sequencing. he development of genetic technology has facilitated a rapid implementation of these newer generation technologies into clinical medicine, which signi icantly increases diagnostic rate in symptomatic individuals [1]. Genomic sequencing (GS) is now an essential tool for evaluating rare disorders with estimated detection rate to be $20 \%$ to $45 \%$ depending on the clinical presentation, age of onset, and population $[2,3]$.

Meanwhile, the Affordable Care Act promotes re-focusing on the health of both individuals and communities to decrease the overall cost on medical care. Newborn screening (NBS) was the irst step toward preventive medicine at the population level and started in the 1960s by testing newborns for phenylketonuria (PKU). In the United States, a uniform newborn screening panel was recommended by the American College of Medical Genetics and Genomics (ACMG) in 2006 [4]. he most successful example of NBS in the USA is cystic ibrosis (CF) which has in luenced the lives of many due to high frequency; however, the clinical utility in some disorders such as Krabbe disease is still controversial [5]. More recently, noninvasive prenatal testing (NIPT)/circulating free DNA (cfDNA; also called liquid biopsy) testing revolutionized prenatal and oncological screening tests. hese tests have made the diagnosis less invasive.

Carrier-screening (CS) has extended efforts to the preconception level in high risk populations. he most widely used and mature CS in the USA is for CF in Caucasian and a multiple gene hotspot panel for Ashkenazi Jewish. Nowadays the expanded CS includes other less common disorders that are prevalent in minorities and is considered part of precision medicine. For this reason, the expanded carrier screening (ECS) was accepted by the American College of Obstetricians and Gynecologists (ACOG) [6].

Another major achievement in clinical molecular genetics was the expansion of diagnostic and prognostic tests to therapy-related screening for drug selection, pharmacogenomics (PGx), which is a key component of personalized therapy. Statistics show that 1 of 5 injuries or deaths per year to hospitalized patients may be as a result of adverse drug reactions [7]. A wide range of gene variants are related to drug selection, such as single nucleotide variants (SNVs; such as CYP2B6, CYP2C9, HLA-B ${ }^{*}$ 57:01), deletions (CCR5- $\Delta 32$ allele), ampli ications (HER2), and gene rearrangements (BCR-ABL1, ALK). herapeutic targets (such as cetuximab/panitumumab and KRAS; vemurafenib and BRAF) and predisposition to certain drug side effects (abacavir and HLA-B 5701 ; carbamazepine and HLA-B ${ }^{*} 1502$; thiopurines and TPMT) are both considered parts of PGx in this communication [8]. 
Citation: Meng H, Xu W (2018) Clinical Molecular Genetic Laboratory Practice, Where We Stand in 2018. J Mol Genet Med 12: 368 . doi: $10.4172 / 1747-0862.1000368$

Page 2 of 2

The increased frequency and complexity of clinical molecular genetic tests across the nation make regulation challenging especially since a majority are laboratory developed tests (LDTs). In 2010, the FDA announced its intent to reconsider its policy of enforcement discretion for LDTs and held a workshop to obtain input from stakeholders on such policy. The FDA used this feedback to develop an initial draft approach for LDT oversight and published draft guidance in 2014. Existing nondiscrimination provisions such as the Health Insurance Portability and Accountability Act (HIPAA) generally prohibits health insurers or health plan administrators from requesting or requiring genetic information of an individual or the individual's family members. In 2008, a federal law, GINA (Genetic Information Nondiscrimination Act), was implemented to further protect individuals from genetic discrimination in health insurance and employment. In the past 10 years, public awareness of GINA has increased in response to the dramatically growing genetic testing $[9,10]$.

However, we are facing tremendous challenges in the preliminary period of the "genomic era". Awareness of a standardization of NGS tests such as validation and quality control are emerging, but not yet fully developed [11-14]. Furthermore, underdeveloped public databases limit the clinical interpretation of patient's results. A costeffective follow-up testing strategy for cancer surveillance still falls into the blind site if the variant is not common. Collaborative oversight of LDTs between, FDA, ACMGG, CAP (College of American Pathology), and CLIA'88 (Clinical Laboratory Improvement Amendments of 1988) is still under discussion and developing. While we work together to navigate in the genomic era, one thing is certain: personalized medicine will continue to positively impact patient care and health system.

\section{References}

1. Katsanis SH, Katsanis N (2013) Molecular genetic testing and the future of clinical genomics. Nat Rev Genet 14: 415-426.
2. Krier JB, Kalia SS, Green RC (2018) Genomic sequencing in clinical practice: Applications, challenges, and opportunities. Dialogues Clin Neurosci 18: 299-312.

3. Vivante A, Ityel H, Pode-Shakked B, Chen J, Shril S, et al. (2017) Exome sequencing in Jewish and Arab patients with rhabdomyolysis reveals single-gene etiology in 43\% of cases. Pediatr Nephrol 32: 2273-2282.

4. Watson MS (2006) Current status of newborn screening: decision-making about the conditions to include in screening programs. Ment Retard Dev Disabil Res Rev 12: 230-235.

5. Orsini JJ, Saavedra-Matiz CA, Gelb MH, Caggana M (2016) Newborn screening for Krabbe's disease. J Neurosci Res 94: 1063-1075.

6. Committee on G (2017) Committee Opinion No. 690: Carrier Screening in the age of genomic medicine. Obstet Gynecol 129: e35-e40.

7. Leape LL, Brennan TA, Laird N, Lawthers AG, Localio AR, et al. (1991) The nature of adverse events in hospitalized patients. Results of the Harvard medical practice study II. N Engl J Med 324: 377-384.

8. Schwab M, Schaeffeler E (2012) Pharmacogenomics: A key component of personalized therapy. Genome Med 4: 93.

9. Rothstein MA (2018) GINA at ten and the future of genetic nondiscrimination law. Hastings Cent Rep 48: 5-7.

10. Parkman AA, Foland J, Anderson B, Duquette D, Sobotka H, et al. (2015) Public awareness of genetic nondiscrimination laws in four states and perceived importance of life insurance protections. J Genet Couns 24: 512-521.

11. Aziz N, Zhao Q, Bry L, Driscoll DK, Funke B, et al. (2015) College of American Pathologists' laboratory standards for next-generation sequencing clinical tests. Arch Pathol Lab Med 139: 481-493.

12. Kalman LV, Datta V, Williams M, Zook JM, Salit ML, et al. (2016) Development and characterization of reference materials for genetic testing: Focus on public partnerships. Ann Lab Med 36: 513-520.

13. Jennings LJ, Arcila ME, Corless C, Kamel-Reid S, Lubin IM, et al. (2017) Guidelines for validation of next-generation sequencing-based oncology panels. J Mol Diagn 19: 341-365.

14. Roy S, Coldren C, Karunamurthy A, Kip NS, Klee EW, et al. (2018) Standards and guidelines for validating next-generation sequencing bioinformatics pipelines. J Mol Diagn 20: 4-27. 